\title{
Elustiil ja tervis preindustriaalses linnas
}

Rebecca Storey

\section{Sissejuhatus}

Üheks ol ulisimaks verstapostiks inimkonna ajal oos on ol nud linnade tekkimine ja nende muutumine inimeste põhiliseks elukohaks ning ühiskonna administratiivseks ja majanduslikuks südameks. Linnastumisega kaasnenud muutused inimasustuses ja elukorralduses olid sedavõrd märkimisväärsed, et V. Gordon Childe (1950) andis neile nimetuse urbanistlik revolutsioon. Linnas el amine erineb märkimisväärselt külas elamisest, peamiselt just tihedama asustuse ning elanike majandusliku, sotsiaalse ja etnilise mitmekülgsuse poolest. Lisaks ei ole linnaasukad füüsiliselt võimelised endal e ise kõi ki elatusvahendei d tootma ja sõltuvad lähedalasuvatest või toetavatest maapi irkondadest, mis varustavad neid toiduga. Seega esindas tekkiv linnakeskkond väikeste põllumajanduslike küladeja asulatega võrrel des uut elustiili nii el upaiga, elatumisallikate kui ka sotsiaalse läbikäimise viiside poolest. Ilmusid ka uued rahvastiku- ja tervisemudelid ning nendega kaasnevad ohud. J ust neid aspekte käesolevas artiklis käsitletaksegi.

J uba mõnda aega eristavad sotsiaalteadlased ja ajaloolased preindustriaalseid ja industriaalseid linnu. Viimased on hiljutine nähtus, milletekkimisel eaitasid kaasa industrial iseerimine, kasvav kontroll elutute energiaallikate üle, keerulisemad tööriistad ning teaduslike avastuste rakendamine kaupade tootmisel ja teenuste pakkumisel. Sõna preindustriaal ne viitab linnakeskustele, mis sõltuvad enamasti inim-ja loomsetest energiaall ikatest (Sjoberg 1960). Kuni 18. sajandi al guseni eksisteerisid Euroopas vaid preindustriaalsed linnad ja need on ol nud inimkonna ajal oos levinuimaks linnakeskkonna liigiks. Väidetavalt leidub madalama arengutasemega riikides tänapäevalgi preindustriaal seid linnu. Käesol evas töös käsitletakse ainult neid preindustriaal seid linnu, mis pärinevad tööstusrevolutsioonieelsest ajast.

http://haldjas.folkl ore.ee/tagused/nr22/storey.pdf 


\section{Tervis ja suremus E uroopa preindustriaalsetes linnades}

Preindustriaalsed linnad on ajal oos muutunud nii geograafiliseasukoha kui ka kultuuri poolest ning neid ei saa pidada ühtseks kogukonnatüübiks. Nende määratlemine kultuuriüleselt on tekitanud juba varem vaidlusi ja on senini arutluse teemaks (Sjoberg 1960; Fox 1977; Sanders \& Webster 1988). Keskused erinevad üksteisest suuruse, administratiivseteülesanneteliikideja keerulisusening kaubanduslike ja majanduslike toi mingute iseloomu poolest. Tavaliselt on sellistelinnadeelanikkond võrreldes tänapäeva linnakooslustega väike(Sjoberg 1960), osal eneist on isel oomulik spetsial iseerumine valitsemiseleehk admi nistreerimisele, teistele kaubavahetus ja turupaigad (Fox 1977; Sanders \& Webster 1988). Näiteks E uroopa preindustriaal seid linnu võib majanduslikeja administratiivsete funktsi oonidealusel liigitada muinasaegseteks, keskaegseteks ja varauusaegseteks, kuigi tegelikult pakub sotsiaalteaduslikust vaatepunktist huvi hoopis E uroopa linnastumisprotsessi areng (Vries 1984).

Vaatamata sellele, et preindustriaalstelinnade elanikkonnad erinevad sotsiaal kultuuriliste tunnuste poolest, on nende demograafilised ühisjooned hästi teada ja neid nimetataksel innaelanikkonna loomuliku kahanemiseseaduseks ${ }^{1}$ (Vries 1984). Enne, kui tööstusrevolutsioon tõi kaasa hüppe meditsiinis ja tervishoius, oli suremus linnades väga kõrge ja keskmine eluiga lühem kui maapiirkondades. Sageli ületas surmade arv sündide oma ja linnarahvastik ei suutnud end ise taastoota, vajades seega oma püsimajäämiseks ja kasvuks immigratsiooni maapiirkondadest (Wrigley 1969; Davis 1973; McNeill 1976). Arvatakse, et kõrge suremus, eriti imikute ja laste seas, tulenes kahest põhifaktorist: haiguste koorem oli tiheda asustuse kohta liialt raske - sanitaartingi mused ja hügieenivõi malused ol id sellega toi metulekuks ebapi isavad, teiseks vaevasid linnael anikkealatoitumus ja üldsekehvapool netoitumine, mis sõltus maapi irkondadesuutlikkusest linnu toiduainetega varustada (Wrigl ey 1969; McNeill 1976). Haiguste laia leviku põhjustasid eelkõige nakkused, näiteks leetrid ja hingamisteede haigused, mis kandusid tihedalt paikneva elanikkonna seas kiiresti edasi. Ka vesi oli preindustriaalsetes linnades tiheda asustuse ja kehvade sanitaartingimuste tõttu sageli reostatud, mistõttu vees elavad haigustekitajad olid pidevas ringluses ja nakatasid inimesi üha uuesti (McNeill 1976). 


\section{Rebecca Storey}

Tabel 1. Suremusenäitajad nejjas Londoni koguduses (1000 inimesekohta).

\begin{tabular}{|c|c|c|c|c|}
\hline & Vanus & $\begin{array}{l}\text { Ellu- } \\
\text { jää- } \\
\text { nuid }\end{array}$ & $\begin{array}{l}\text { Surnu- } \\
\text { te suht- } \\
\text { arv }\end{array}$ & $\begin{array}{c}\text { Eeldatav eluiga } \\
\text { sünni- } \\
\text { momendil }\end{array}$ \\
\hline \multicolumn{5}{|l|}{ J õukad } \\
\hline \multirow[t]{5}{*}{$\begin{array}{l}\text { Cornhilli Püha } \\
\text { Peetruse kogudus }\end{array}$} & 0 & 1000 & 200 & $34-36$ \\
\hline & 1 & 800 & 148 & \\
\hline & 5 & 682 & 46 & \\
\hline & 10 & 651 & 31 & \\
\hline & 15 & 631 & & \\
\hline \multirow[t]{5}{*}{$\begin{array}{l}\text { Cornhilli Püha } \\
\text { Miikaeli kogudus }\end{array}$} & 0 & 1000 & 203 & 29-31 \\
\hline & 1 & 797 & 156 & \\
\hline & 5 & 673 & 83 & \\
\hline & 10 & 617 & 34 & \\
\hline & 15 & 596 & & \\
\hline \multicolumn{5}{|l|}{ Vaesed } \\
\hline \multirow{5}{*}{$\begin{array}{l}\text { Somerseti Püha } \\
\text { Neitsi Maarja } \\
\text { kogudus }\end{array}$} & 0 & 1000 & 265 & 21 \\
\hline & 1 & 735 & 246 & \\
\hline & 5 & 554 & 93 & \\
\hline & 10 & 502 & 21 & \\
\hline & 15 & 467 & & \\
\hline \multirow[t]{5}{*}{$\begin{array}{l}\text { London Walli Kõigi } \\
\text { Pühakute kogudus }\end{array}$} & 0 & 1000 & 242 & $24-26$ \\
\hline & 1 & 758 & 208 & \\
\hline & 5 & 600 & 104 & \\
\hline & 10 & 538 & 56 & \\
\hline & 15 & 508 & & \\
\hline
\end{tabular}

Mugandatud R. Finlay (1981) tabelite 5.7-5.15 järgi. 
Kahaneva linnarahvastiku mudel toetub paljudele ebateaduslikele väidetele, seepärast leidub ka kriitikat seisukohale, et linnad olid loomupäraselt võimetud oma elanikkonna suurust säilitama. Allan Sharlin (1978) leiab, et E uroopa preindustriaalsetelinnade kirjalikes allikates ületab surmade arv sündide oma seetõttu, et paljud sisserändajad kuulusid ühiskonna madalamatesse kihtidesse- olid teenijad, õpipoisid jne - ning ei abiellunud ega sulandunud linnaühiskonda. Sellest tulenevalt ei suurendanud nad kuigivõrd sündide arvu, küll aga kasvatasid surmade statistikat. Linna püsielanikud oleksid suutnud tagada elanikkonna loomuliku kasvu, kui seda poleks tasakaalust välja viinud sisserännanute kõrge suremus. A. Sharlini väide viitab sellele, et linnade ülikõrge suremus tulenes sisserändest, mitte linnakeskkonna kui sellise laastavast mõjust. Antud vaatenurgast lähtudes sattusid linnad just seoses sisserändajate ligimeelitamisega demograafilisse madalseisu, sest nood mittee tasakaalustanud el anikkonna vähenemist, vaid aitasid hoopis reaalselt kaasa kõrge suremuse tekkimisele.

Tõttöel da on vähesell iseid ajal ool ise demograafia uurimusi, mis oleksid rakendanud tänapäevaseid kvantitatiivseid meetodeid ja tõestanud, et linnades ületas suremus sündimuse (V ries 1984). See puudujääk on tingitud asjaolust, et sellistelinnauurimusteläbi viimiseks on vaja suurt hulka kirjalikke andmeid. Linnakeskustele omaseid arvukaid sisserändajaid on demograafilises andmestikus aga raske tuvastada, sest nad ei ole linnas sündinud ja ilmuvad linna kirjalikesse ürikutesse alles täiskasvanutena. Mõned viimase aja usal datavad kvantitatiivsed uurimused si iski toetavad linnael anikkonna loomuliku kahanemise seadust ja lükkavad A. Sharlini väited ümber.

Roger Finlay (1981) kasutas selleks, et määrata kindlaks preindustriaalse Londoni suremus ja sündimus ajavahemikus 15801650, meetodit, kus ta seostas kirikumeetrikast pärinevad inimeste ristimis- ja surmasissekanded ning leidis, et antud rühmade puhul oli suremus tõesti sündimusest kõrgem. R. Finlay kasutas vaid alla 15-aastaste andmeid, sest ülestähendused nende kohta olid kõige täielikumad - sisseränne toob kaasa selle, et paljude täiskasvanute kohta lei dub andmestikus vaid nende surmadaatum, mitte aga sünniaeg. Tabelis I on toodud R. Finlay arvutused ellujäänud, surnud ja oodatavad el uead sünnimomendil. Loendused on tehtud kahejõuka (Cornhilli Püha Peetruseja Püha Miikaeli) koguduse ning kahevaesema (Somerseti Püha Neitsi Maarja ja London Walli 


\section{Rebecca Storey}

Kõigi Pühakute) koguduse kohta (vt tabel 1). I mikute suremus oli kõigis neljas koguduses suur - madalaim suremuse tase oli $20 \%$ esimese eluaasta jooksul. E eldatav eluiga sünnimomendil varieerus 21 eluaastast umbes 35 eluaastani, sealjuures ol id erinevused jõukamate ja vaesemate koguduste vahel märkimisväärsed.

Kui võrrelda neid andmeid nelja tolleaegse Inglismaa külaga, oli laste suremus isegi jõukates linnakogudustes neist suurem. Külades oli laste suremus keskmiselt $12 \%$ ja eel datav eluiga sünnimomendil vähemalt 41 aastat (Finlay 1981: tabel 5.5). R. Finlay järeldas, et imikute ja laste suremus oli Londonis tunduvalt kõrgem kui ümberkaudsetes külades.

Londoni rahvaarvu kahanemise hindamiseks võrreldi ristimiste ja matuste hulka kümnes Londoni koguduses (Finlay 1981: 59). Kui jõukates kogudustes olid ristimised ja matmised enam-vähem tasakaalus, siis vaesemates kogudustes tuli iga matmise kohta vaid 0,7 ristimist. Üldine keskmine oli 0,87 ehk ristimisi oli 13\% võrra vähem kui matmisi. Enamik elanikkesuri linnas lapse, mittetäiskasvanuna, nagu eel daks A. Sharlini mudel (1978). Seega või b nende andmete põhjal järeldada, et Londoni püsielanikkond vähenes ja 16. ja 17. sajandi elanikkonna kasvu põhjustas tõenäol iselt migratsioon (Finlay 1981).

Anal oogseid demograafilisi näitajaid ajavahemi kus 1777-1797 on kirjalikest allikatest leitud ka Amsterdami kohta (Vries 1984). Seal ol i vastsündinute suremus $29 \%$; lisaks suri $27 \%$ enne viiendat eluaastat. Neid andmeid on võimalik analüüsida mudel ipõhiste elutabelite abil: kõige paremini on nad kooskõlas tabelitega, kus eel datav eluiga sünnimomendil jääb vahemikku 23 ja 26 eluaastat. Antud perioodi l oli sündimuskordaja 1000 el ani ku kohta 32,3 ja suremuskordaja 1000 elaniku kohta 39,5 (Vries 1984: 368) - rahvastik vähenes seega aastas 7,2 inimese võrra 1000 inimese kohta.

Vastuseks A. Sharlinile (1978) leidis J an deVries, et sisserännanud sõlmisid tõepool est pi sut vähem abielusid ja olid abiel ludes pisut vanemad kui linna püsielanikud, kuid need asjaolud ei tinginud leitud rahvaarvu kahanemist (Vries 1984: 189-191). Amsterdamis, nagu Londoniski, oli suremus kõige kõrgem vastsündinuteja laste hulgas, mittetäiskasvanute seas (Vries 1984: 193).

Preindustriaalses Genfis avaldasid suremusele märgatavat mõju sotsiaal-majanduslikud tingimused. Uurides ajavahemikku 1625-1684, leiti, et erinevate ühiskonnakihtide ${ }^{2}$ eeldatav eluiga sünnimomendil varieerus rikasteja vaestevahel 16 aasta võrra (35,9 aastat kõrgklassi 
ja 18,3 aastat lihttöölistepuhul (Perrenoud 1975: 236)). See seaduspära sarnaneb 17. sajandi Londonile, kus erinevus ulatus vähemalt viiest aastast isegi kuni 15 aastani (vt tabel 1). Preindustriaalseid linnu iseloomustas vastsündinute ja laste kõrge suremus, mida erinevused ühiskonnakihtidevahel veel gi suurendasid. J ust vaestest ühiskonnakihtidest pärit vastsündinuteja laste kõrgesuremus põhjustas üldise rahvaarvu vähenemise(Vries 1984; Finlay 1981).

Selline suremusvanuste jaotus ja püsielanikkonna vähenemine iseloomustasid linnakeskusi kuni tööstusrevolutsioonini, mille järel sanitaar-ja toitumistingimused paranesid (Wrigley 1969; M cNeill 1976). Paljudel juhtudel jõuti nii kaugele alles 20. sajandi alguses (Davis 1973).

\section{Paleopatoloogilised tõendid}

Kui preindustriaalse linna elustiil mõjus tõepoolest laste tervisele hävitavalt, võib eel dada, et see kajastub peal esurmajuhtumitestatistika ka muudes allikates. Kui haigused ja alatoitumine on peamiseks kõrge suremuse süüdlaseks, siis peaks luustiku seisund viitama imiku- ja lapseeas põetud haigustele. Eriti kasulikud võiksid predindustriaalselinna elustiili mõjude hindamisel olla mittespetsiifilised stressile viitavad märgid. Need märgid kajastavad lapsepõlves aset leidnud kasvu- ja paranemishäireid või kasvu peatumi si, mille on põhjustanud kehv toitumine, mõni hai gus või mõlema sünergiline koostoime (Huss-Ashmore \& Goodman \& Armelagos 1982). Need on mittespetsiifilised selle poolest, et kasvuhäire täpset põhjust ei ole võimalik kindlaks määrata, sest mitmed erinevad haigused ja vaegused jätavad luustikku ühesuguse märgi.

Antud artiklis analüüsitavad mittespetsiilifised stressile viitavad märgid on transversaal sed jooned ja hambavaaba hüpoplaasiad. Transversaal sed jooned on tumedad kitsad jooned toruluudel - eriti jalaluudel - , mis on nähtavad röntgenogrammi abil. Hambavaaba hüpoplaasiad on hammastel leiduvad lineaarsed säl gud või augud (vt joonis 1). Selliste märkide eel iseks on see, et need võivad esineda nii sünnieelselt kui ka -järgselt kogu kasvu- ja kujunemisperioodi vältel ning annavad seega täieliku ülevaate imiku- ja lapseea arenguetappidest. Kindlaks saab määrata ka vanuse, millal kasv peatus. See võimal dab uurida vanuselisi iseärasusi - episoodide kõrgeim esinemissagedus mingis kindlas vanuses viitab võima- 


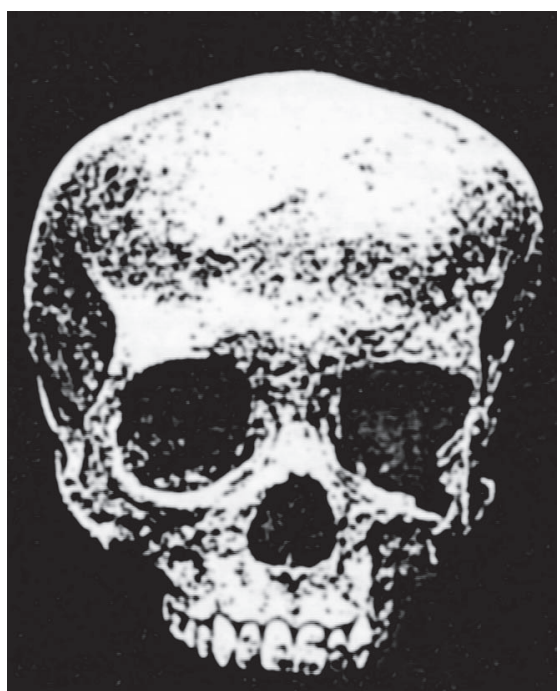

J oonis 1. Tlajinga 33st pärit alaealise koljuluu. See on näide ühest paremini säilinud luusti kust sel les kvartalis. I nimesel esinesid hüpoplaasiad - üks on nähtav paremal silmahambal, teised on antud pi ldil hambakivi tõttu ähmaselt nähtavad. likeleelustiilist tingitud stressoritele (Goodman \& Martin \& Armelagos \& Clark 1984).

Preindustriaal setest linnadest pärinev luustikuline materjal on paraku haruldane, eriti eespool vaatluseall ol nud Euroopa linnade osas. Üht kalmistut, mis asus Kolumbuseeelses - ja seega preindustriaalses - Kesk-Mehhikos paiknevas Teotihuacani linnas (u $150 \mathrm{eKr}-750 \mathrm{pKr}$ ), on siiski lähemalt uuritud just eesmärgiga leida otseseid tõendeid preindustriaalsetelinnadeelustiili kodeeritud haigestumuse ja suremuse kohta. Teotihuacani rahvaarv ulatus kõrgajal, umbes 400.-700. aastal eKr 125 000-200 000 inimeseni (Millon 1981), millega ta kuulus tollal maailma suurimate linnade hulka (Chandler \& Fox 1974). Olgu veel märgitud, et Teotihuacan oli ka Kesk-Ameerika varaseim linnaühiskond.

Ehkki Teotihuacan tundub ol evat sobiv kandidaat linna el ustiilist tingitud stressi uurimiseks luustike põhjal, tuleb lisada, et Kolumbuse-eelsele Uuele Maailmale olid isel oomulikud Vanast Maailmast erinevad haigused. See võib tähendada, et seal ne tihedalt paiknev rahvastik ei pruukinud kannatada samasuguse haigustekoorma all nagu Vana Maailma linnad. Tundub, et erinevalt Vanast Maailmast jäi Kesk-Ameerika suhtel iselt puutumata nakkuslikest massiepideemiatest (nt tuulerõuged ja leetrid) (Cook 1946; Newman 1976). Kokkupuutel eurooplastega andsid Uue Maailma elanikud neileilmselt edasi vaid ühe tõsisema haigusesüüfilise (Baker \& Armelagos 1988) - , samas kui eurooplaste toodud haigused laastasid sealseid el anikke tõsiselt (Newman 1976; Dobyns 1983; Crosby 1972). Kesk-M ehhiko vallutusele eel nevast peri oodist on küll teada epi deemilise surma juhtumeid, kuid neid 
saab seostada vaid näljahäda ja selle tagajärgedega (Cook 1946). Val davad haigused ja haigustekitajad olid seedeel undkonna ja hingamisteede nakkused, mitmesugused troopilised palavikud, mittesugulisel teel leviv süüfilis, tuberkuloos, parasiidid, stafülokokid ja streptokokid ning toidumürgituse tekitajad (Newman 1976; Cook 1946). Neile on iseloomulik pigem endeemiline kui epideemiline nakatumisviis (N ewman 1976).

Teotihuacani tihedalt paiknevat elanikkonda võisid seega ohustada pigem alatoitumus ja endeemilised nakkused kui Vana Maailma linnadel eiseloomulikud nakkusepideemiad. Antisanitaarseid elamistingimusi, veereostust ja vees ringl evaid nakkusi tõenäol iselt siiski esines, seega seisid Teotihuacani elanikud silmitsi samade ohtudeja suremusega nagu teisedki preindustriaal sed linnad (Storey 1985).

Siinkohal analüüsitav luustikurühm koosneb 206 indiviidist, kelle vanust on võimal ik kindlaks määrata. Need leiti Teotihuacani tüüpilisest alama klassi el ukvartalist (kvartali täpsemat kirjeldust vt Storey 1985). K vartalis Tlajinga 33 elasid kiviraiduritest käsitööl ised, kes viimase kahesajandi jooksul (praeguste hinnangutekohaselt 200.- 700. a eK r) val mistasid ka keraamikat. K vartali väljakaevamistelt ei leitud mingeid märke maaharimisriistade olemasolust, seega või b arvata, et elanikud sõltusid enda toiduga varustamisel peamiselt linnaturust.

Tlajinga 33 väljakaevamiste peamiseks eesmärgiks oli lei da luustikurühm, mis ol eks demograafil ise analüüsi läbiviimiseks piisavalt suur. Otsiti hoolega matmispaiku ja luid ning kõiki matuseid uuriti suure põhjal ikkusega, et saada kättevõi mal ikult palju luustikufragmente. See tehnika oli eriti oluline selleks, et avastada imikute ja lasteluustikke. Paraku olid paljud luustikud fragmentaarsed - eriti need, mis leiti ühismatustest ja jäätmekuhilatest. Uurijad püüdsid kõiki allikaid hool ikalt kontrollida ja ol emasol evaid luustikuosi maksimaalselt ära kasutada. Paljudeluustike kehvale seisukorralevaatamata oli võimalik identifitseerida teatav hulk isikuid. Samas olid pal eopatol oogiliste uurimuste val imitesuurused pi iratud, sest paljude isikute puhul puudusid uurimiseks vajal ikud luud.

Ehkki Tlajinga 33 luustikurühm esindab vaid väikest osa linnarahvastikust, annab see teavet alama klassi käsitöölistekohta, kes sarnaselt Londoni ja Genfi vaesematele el anikele kannatasid tõenäoliselt teistest enam linnaelu ebatervislikemõjude all. Antud oletuse kontrollimiseks ol eks vaja kindlaks määrata, kas imikute ja laste suremus ol i Tlajinga 33s ja Euroopa preindustriaalsetes lin- 


\section{Rebecca Storey}

Tabel 2. Üldinevanusel inejaotus Tlajinga 33. kvartalis võrdluses teisteUue Maailma luustikurühmadega.

\begin{tabular}{|l|c|c|c|c|c|}
\hline Rahvastik & $\begin{array}{c}\text { Uuritava- } \\
\text { te hulk }\end{array}$ & $\begin{array}{c}\text { Väike- } \\
\text { lapsed }\end{array}$ & $\begin{array}{c}\text { Alaea- } \\
\text { lised }\end{array}$ & $\begin{array}{c}\text { Nooru- } \\
\text { kid }\end{array}$ & $\begin{array}{c}\text { Täiskas- } \\
\text { vanud }\end{array}$ \\
\hline Tlajinga 33 & 206 & $31 \%$ & $14 \%$ & $9 \%$ & $46 \%$ \\
\hline Pecos Pueblo* & 1722 & $18,7 \%$ & $14 \%$ & $8 \%$ & $59 \%$ \\
\hline $\begin{array}{l}\text { Libben } \\
\text { (Põhja- } \\
\text { Ohio)** }\end{array}$ & 1289 & $18 \%$ & $22 \%$ & $14 \%$ & $46 \%$ \\
\hline $\begin{array}{l}\text { Hiwassee } \\
\text { (Dallas)*** }\end{array}$ & 437 & $38 \%$ & $20 \%$ & $12 \%$ & $29 \%$ \\
\hline $\begin{array}{l}\text { Gasas Gran- } \\
\text { des**** }\end{array}$ & 612 & $10 \%$ & $22 \%$ & $14 \%$ & $54 \%$ \\
\hline $\begin{array}{l}\text { Arikara } \\
\text { külad***** }\end{array}$ & 148 & $31,55 \%$ & $24 \%$ & $9,5 \%$ & $35 \%$ \\
\hline
\end{tabular}

* Mubley 1980; ** Lovejoy et al. 1977; *** Lewis \& Kneberg 1946; **** Benfer 1968; ***** Owsley \& Bradtmiller 1983.

nades ühesugune. Selleks aga, et luustikurühm ol eks antud demograafilise järelduse tegemiseks otstarbekas, peaks see esindama kogu päritol upaiga el anikkonda. Seetähendab, et luustikulises valimis peab ol ema piisavalt esindatud iga vanuserühmja ei tohi olla tõendeid ühegi vanuserühma si hilikust väljajätmisest. Tabelis 2 on toodud suremuse vanuseline jaotus Tlajingas võrrel duna teiste teadaol evate Uue Maailma luustikurühmadega, mida teadlased on pidanud nõuetel e vastavaks. Kuigi andmed on üldjoontes sarnased, isel oomustab Tlajinga rühma imikute suur osa - 31\% valimist. $40 \%$ kogu valimist on alla viieaastased ja 50\% 15-aastased või nooremad. Kui paljude luustikuliste valimite puuduseks peetakse sageli imikute vähest esindatust (vrd Buikstra \& Konigsberg 1985), siis Tlajinga 33 puhul seda probleemi ei ole.

Esmapilgul tundub, et imikute ja laste osa on sarnane tabelis 1 toodud Londoni näitajatega ja kõrgem kui enamiku teiste Uue Maailma rahvastike puhul, kui välja arvata hilisem Mississippi Hiwassee (Dallas) elanikkond ja ajaloolised Arikara külad, mida mõjutasid Kolumbuse-järgsed uued haigustekitajad. Samas on ai- 
nuüksi suremisvanusel põhinevad tõendid teistsugust tüüpi demograafilise sisuga kui põhiliselt ellujäänutele toetuvad andmed (J ohansson \& Horowitz 1986). Teadl ased on hiljuti jõudnud arusaamisele, et pal eodemograafil ist materjali ei saa otseselt tõl gendada samade mõõdupuude alusel nende rahvastike kohta käivate demograafiliste andmetega, mida tuntakse valdavalt rahvaloenduste ja elulemusstatistika põhjal. See on võimalik vaid juhul, kui elanikkond, kust luustikud pärinevad, oli stabiilneja muutumatu, s.t seda iseloomustasid stabiilnesuremus ja sündimus ning rahvaarv ei kasvanud ega kahanenud (J ohansson \& Horowitz 1986). J uhul, kui luustikulineval im pärineb sell ist tüüpi muutumatust rahvastikust, peegeldab surnute protsent igas vanuserühmas otseselt suremise tõenäosust selles vanuses. J ärelikult saab luustike suremusvanustejaotuse abil otseselt mõõta suremust minevikus. Viimane kehtib vaid siis, kui rahvaarv ei kasva ega kahane.

Pal eodemograafias on stabiilsuse eel damine ol nud üsna taval ine - võttes arvesse arheol oogilise mineviku pikki ajavahemikke, vastab see enamasti tõele, sest asulad kasvasid vähe või väga aeglaselt. Samas pärinevad paleodemograafilised luustikurühmad enamasti arheol oogilistest leiukohtadest, mi s hõlmavad kasvu- või kahanemistendentside kajastamiseks piisavalt lühikesi ajavahemikke. Selle tulemusena on paleodemograafia hiljuti muutunud, György Acsádi ja J ános Nemeskéri (1970) aegade tavapraktika enam ei kehti.

Lisa Sattenspiel ja Henry Harpending (1983) osutavad, et tegelikult võib ühe asustuse suurem imikute hulk võrrel des mõneteisega viidata lihtsalt sellele, et suurema vastsündinute arvuga asustus kasvab. Suurema sündide arvuga kooslustes esineb ka proportsionaalselt rohkem suremist. Seda ei põhjusta aga suremuse kasv - noorte osa suurenemine rahvastikus suurendas ka nende osa surnute hulgas (J ohansson \& Horowitz 1986). Kasvavat elanikkonda isel oomustab proportsionaalselt suurem noorte hulk ja see peegel dub ka suremuse vanuselises jaotuses. Seega on suremuse mõõtmiseks suremi svanuste põhjal vaja arheol oogilist hinnangut rahvasti ku kasvu või kahanemise taseme kohta - see või maldaks täpselt tõlgendada, mi da erinevad suremuse osakaalud vanuserühmades tegel ikult näitavad (J ohansson \& Horowitz 1986). Teisisõnu tähendab see, et ainuüksi alaealiste suurest hulgast Tlajingas ei piisa suremuse määramiseks, sest ainult luustike vanuselise jaotumise põhjal ei ole võimalik öelda, kas rahvaarv kahanes. 


\section{Rebecca Storey}

Tabe 3. Statsi onaarsuse eel dusel koostatud elutabel Tlajinga 33. kvartali elanikekohta.

\begin{tabular}{|l|r|l|l|l|l|l|l|}
\hline Vanus & \multicolumn{1}{|l}{$\mathbf{D}_{\mathbf{x}}$} & $\mathbf{d}_{\mathbf{x}}$ & $\mathbf{I}_{\mathbf{x}}$ & $\mathbf{q}_{\mathbf{x}}$ & $\mathbf{L}_{\mathbf{x}}$ & $\mathbf{T}_{\mathbf{x}}$ & $\mathbf{e}_{\mathbf{x}}$ \\
\hline Vastsündinud & 55 & 0,27 & 1000 & 0,27 & 144 & 20492 & 20,49 \\
\hline I mikud & 8 & 0,04 & 730 & 0,05 & 592 & 20348 & 27,87 \\
\hline 1 & 18 & 0,09 & 690 & 0,13 & 2580 & 19756 & 28,63 \\
\hline 5 & 11 & 0,05 & 600 & 0,08 & 2875 & 17176 & 28,63 \\
\hline 10 & 10 & 0,05 & 550 & 0,09 & 2625 & 14301 & 26 \\
\hline 15 & 9 & 0,04 & 500 & 0,08 & 2400 & 11676 & 23,35 \\
\hline 20 & 16 & 0,08 & 460 & 0,17 & 2100 & 9276 & 20,17 \\
\hline 25 & 8 & 0,04 & 380 & 0,11 & 1800 & 7176 & 18,88 \\
\hline 30 & 7 & 0,03 & 340 & 0,09 & 1625 & 5376 & 15,81 \\
\hline 35 & 12 & 0,06 & 310 & 0,19 & 1400 & 3751 & 12,1 \\
\hline 40 & 22 & 0,11 & 250 & 0,44 & 975 & 2351 & 9,4 \\
\hline 45 & 11 & 0,05 & 140 & 0,36 & 575 & 1376 & 9,83 \\
\hline 50 & 11 & 0,05 & 90 & 0,56 & 325 & 801 & 8,9 \\
\hline 55 & 3 & 0,015 & 40 & 0,38 & 163 & 476 & 11,9 \\
\hline 60 ja vanemad & 5 & 0,025 & 25 & 1,0 & 313 & 313 & 12,5 \\
\hline KOKKU & 206 & 1,0 & & & & & \\
\hline
\end{tabular}

Tabel erineb varem avaldatud tabelitest sama rahvastiku luustike kohta (näit Storey 1985). Erinevused tulenevad mõningate uute leidude lisandumi sest rahvastikule ning kombineeritud kronol oogiate ja uute täiskasvanute vanuse määramise tehnikate rakendamisest. Surnute vanuselise jaotuse tulemused on seega palju täpsemad kui varem kasutusel olnud.

Elutabeli veerud tähendavad: $\mathrm{D}_{\mathbf{x}}$ - igas vanuseklassis tegelikult olevaid isikuid; $d_{\mathbf{x}}$ - vastavas vanuseklassis surnute suhtarv; $l_{\mathbf{x}}$ - ellujäänute hulk vastavas vanuseklassis 1000 sündinud kohta; $q_{\mathbf{x}}$ - suremise tõenäosus vastavas vanuseklassis; $L_{\mathbf{x}}$ - vastavas vanuseklassis elatavate aastate koguhulk; $T_{\mathbf{x}}$ - aastate koguhulk, mis on jäänud elada isikutel, kes on jõudnud vastavasse vanuseklassi; $e_{\mathbf{x}}$ - vastavasse vanuseklassi jõudnute eel datava edasise eluea pikkus aastates. 
Lisaks tuleb Tlajinga puhul arvestada ka võimaliku sisserändega. Demograafil ised mudelid eel davad enamasti sul etud asustust, nii et enamikulelinnaühiskondadele iseloomulik suur sisserännanute hulk sellise eeldusega ei sobi. Kui suur oli sisserännanute osa Teotihuacani rahvastikus, ei ol eteada, kuid tõenäoliselt on Tlajinga lapsed ja vastsündinud nii sündinud kui ka surnud linnas. J ärelikult peaks keskenduminenendeleindiviididele- nagu Roger Finlay (1981) toimis Londoni puhul - vähendama sisserändest johtuvat eksimistõenäosust.

Nii Teotihuacani linna kui ka Tlajinga 33. kvartali kohta on ol emas arheol oogilised hinnangud rahvaarvu suurenemiste ja vähenemiste kohta. Teotihuacani kasv linnakeskuseks oli kiire: rahvaarv jõudis kõrgpunkti ilmselt varakult - umbes ajavahemikus 150-200 a pKr - ja jäi suhteliselt stabiilselt sellele tasemele püsima kuni järsu vähenemiseni umbes 750. aastal pKr (Cowgill 1979; Millon 1981). Tlajinga 33. kvartali väljakaevamistelt saadud materjalist selgub, et kvartal asutati umbes 200. aastal pKr ning see jõudis oma suurimate mõõtmeteni üsna kiiresti, umbes aastaks 300 pKr. Tlajinga 33 hüljati varem kui enamik ülejäänud linnast. Seega perioodil, mil kvartalis elati, püsis Teotihuacani elanikkond stabiilsena. Kui välja arvata varaseimast asustusajast pärinevad 27 luustikku, siis ül ejäänud luustikumaterjali päritol u aegadel püsis ka Tlajinga 33 suurus stabiilsena. Seega on eeldus, et elanikkond püsis muutumatuna, õigustatud, eriti Tlajinga luustike analüüsi esimeses etapis.

Muutumatuse eel dusel koostatud elutabel, mis koondab kõiki leitud luustikke (tabel 3), näitab väga suurt imi kute ja suhtel iselt suurt lapseealiste suremust. Eeldatav el uiga sünnimomendil on 20,5 aastat, mis on võrreldes E uroopa rahvastikega madal. Sama näitaja tõuseb märgatavalt - 28,6 aastani - laste puhul, kes esimese eluaasta üle elasid. Antud juhul ongi imikuiga kõige ohtlikum periood terve elu jooksul.

Üldised stressinäitajad - hambavaaba hüpoplaasiad, transversaalsed ehk Harrise jooned toruluudel ja kasvukõverad - annavad lisatõendeid selle kohta, et Tlajinga 33 rahvastikus oli laialt levinud stress ja kasvu peatumine hilises looteperioodis. Näiteks olid 16 vastsündinul 19st (84\%) looteeas tekkinud transversaal sed jooned - enamasti ilmusid need kaheksandal või üheksandal raseduskuul. Hambavaaba hüpoplaasiate esinemine piimahammastel näitab sama tendentsi. Valim on väike $(n=14)$, kuid 88 protsendil 


\section{Rebecca Storey}

uuritud rühmast esines hambavaaba hüpoplaasiaid, mis tekkisid sünnieel selt kol me viimase raseduskuu jooksul. Kõi gil imikuea üle elanud lastel, kellel olid veel piimahambad $(n=7)$, esines sünnieelse stressi ilminguid. Lisaks olid 32. rasedusnädalal sündinud enneaegsete imikute toruluud sama suurusega kui õigeaegselt (36. rasedusnädalal või hiljem) sündinutel. Neljanädalane vanusevahe ei mänginud rolli - õigeaegsed lapsed, kes sünnitusel surid, viimase kuu jooksul emaüsas enam ei kasvanud.

Tlajinga 33 vastsündinute ja väikel aste pal eopatol oogiline uurimus viitab emakasisesele stressile ja kasvu aeglustumisele, mille tagajärjel olid imikud raseduse vältel oma vanuse kohta liiga väikesed ja sageli ka sündisid alakaalulistena. Selliste laste seas on suremus ka tänapäeval kõrgem. Vastsündinute skel ettide suur osa luustikurühmas on põhjustatud ilmselt nendest stressoritest. Seega on imikute erakordselt kõrge suremus Tlajinga 33s seletatav luustikulise tõendusmaterjali abil.

Muutumatuse eeldusel koostatud elutabel näitab, et enne 15. el uaastat suri veel $19 \%$ lastest. Suremus on seega ka vanematelaste seas silmatorkav, ehkki tunduvalt väiksem kui vastsündinute puhul. Kõrgeim on suremus 3.-5. eluaastal. Pal eopatol oogilised indikaatorid (jäävhammaste hüpoplaasiad ja transversaalsed jooned) viitavad sellele, et I.-3. el uaasta tõid tavaliselt kaasa piisavalt suure stressi, et häirida normaal seid kasvamisprotsesse (joonis 2). Suurim osa kõi kidest transversaal setest joontest tekkis vanusevahemikus kuuendast elukuust teise el uaastani; mõned jooned ilmnesid ka kol manda ja 17. eluaasta vahel. Suurem hulk hambavaaba hüpoplaasiaid seevastu tekkis pisut hiljem - 2.-3. eluaastal - kuid nende esinemine on suhteliselt sage kuni viienda eluaastani. Transversaal sete joonte põhjuseks peetakse akuutset ja epi soodi list stressi, hambavaaba hüpoplaasiad seevastu võivad tekkida kroonilise stressi tagajärjel (Goodman \& Martin \& Armelagos \& Clark 1984). Mõlema esinemine Tlajinga elanikkonna hulgas viitab sellele, et väikel astel lasuv füsioloogilise stressi koorem oli piisav, et häirida normaalseid kasvuprotsesse või need peatada. 37 luustikust, millel uuriti hambavaaba hüpoplaasiate esinemist, leiti igaühel vähemalt üks hüpoplaasia. Sellised haigusnäitajad tõestavad, et enamik Tlajinga elanikke vaevles varases lapseeas haigusteja/või alatoitumuse käes, ning pakuvad ühe võimal iku sel etuse i mikute ja laste kõrgele suremusel e sell es rahvastikus. 
Muutumatuse eeldusel koostatud suremusmudel ja pal eopatoloogilised tõendid Tlajinga 33st lubavad Teotihuacani vaadelda preindustriaalse linnana, mis sarnanes Euroopa omadega - mõlemaid iseloomustavad imi kute ja laste kõrge suremus ning kasvuhäirete esinemine. I mi kute suremuse tase ja eel datav el uiga sünnimomendil olid aga veel gi kehvemad kui samad näitajad E uroopa linnades.

Tlajinga elutabeli ja Ansley J. Coale'i ja Paul Demeny (1983) mudel ipõhiste elutabel ite suure valimi võrdlus toob esile laste suremusvanuste eripärase jaotuse kõneal uses el anikkonnas. Vastsündinute suremuse tase Tlajingas on vastavuses el utabeli mudeliga (idapiirkonna tabelid algavad näiteks tasemelt 40-50\%). Suremus 1.-5. eluaastal on Tlajingas aga madalam kõigist kõrge suremuse ja madala eel datava eluea tabelitest; seevastu suremus 6.-14. eluaastal on nendega võrrel des kõrgem (vt ka tabel 4). Selliseid erinevusi võisid põhjustada mudeli vead, näiteks suremusealahindamine 1.-5. eluaastal.

On ka võimalik, et Tlajinga elanikkonnas püsis suremuse tase ühtlane kogu lapsepõl ve ja see erines mitmetest teistest rahvastikest, kus suremus oli kõrge enne viiendat eluaastat ja hiljem langes - just selliseid esindavad mudelipõhised elutabelid. Erinevus võib tul eneda ka sellest, et Kolumbuse-eel ses U ues Maailmas domineerisid epidemioloogiliselt endeemilised, mitte ägedad epideemilised haigused, millega on varem seletatud suremuse erinevusi Vana ja Kol umbuse-eel se Uue Maailma vahel (Lovejoy et al. 1977). Pal eopatoloogilised tõendid viitavad püsivalehaiguslikkuselekogu lapsepõlve vältel ja tõik, et enamikul Tlajinga lastest esines mitu stressile vi itavat märki, kinnitab ühtlase suremuse hüpoteesi.

Võttes arvesse eel ki rjel datud suremusmudel it ja pal eopatol oogilisi andmeid Tlajinga laste kohta, tekib küsimus, kas statsionaarsuse eel damine on antud rahvastiku puhul kohane. A. J . Coale'i ja P. Demeny (1983) el utabelid modelleerivad stabiilseid rahvastikke erinevatel kasvu ja languse tasemetel ning näitavad, kuidas jaotuksid vastavalt suremisvanused. Kui neid kohal dada Tlajinga 33 rahvastikule, selgub, et Tlajinga laste ja mudelites toodud suremusvanuste jaotuse vahel on erinevused ja ükski tabel ei sobi täpselt antud luustikurühmaga. Tlajingale isel oomulik vastsündi nute kõrge suremus ja järsk langus I.-5. el uaastal sarnanevad siiski kõige enam kahaneva rahvastiku suremusmudelile (vt tabel 4), sest kõikides A. J . Coale'i ja P. Demeny tabelites toodud kasvavates rah- 
Rebecca Storey

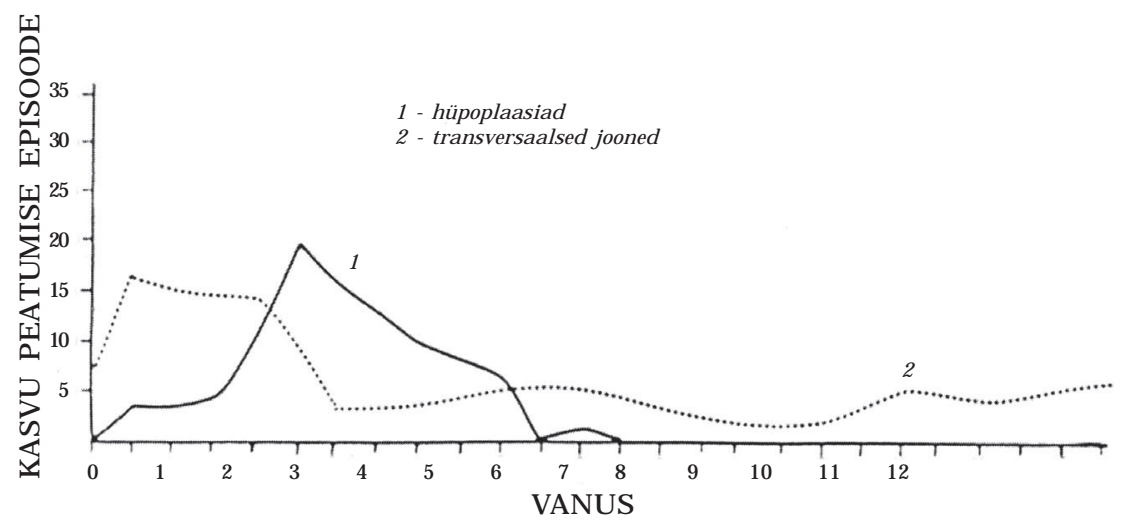

J oonis 2. Hüpoplaasiateja transversaal setejoonteesinemisekõrgperioodid vanuseti. Andmed näitavad märkideesinemi sekoguarvu kõi gil luustikel.

vastikes, kus alla üheaastaste vanuserühmas on suremuse osa umbes $30 \%$, sama näitaja 1-4-aastaste seas on umbes $15 \%$ (vt nt tabel 4). Suundumus on seega erinev sellest, mis ilmneb Tlajingas. Selle rahvastiku suremuse osa 5.-14. eluaastal erineb märgatavalt kõi kidest tabelites toodud näitajatest. Põhja tabelites sarnaneb suremus 5.-9. eluaastal Tlajinga omaga, kuid on vanuses 1-4 aastat märksa kõrgem. Kõrgem suremus 5.-14. eluaastal erineb hiljutiste Euroopa ajal ool iste rahvastike kogemusest, millel põhinevad A. J . Coale'i ja P. Demeny mudelid. E rinevus tuleneb tõenäoliselt Kolumbuse-eelse Uue Maailma keskkonna eripäradest. Sell legi pool est sarnaneb imikute ja 1-4-aastaste laste suremus Tlajinga 33s rohkem kahanevate kui kasvavate rahvastike omale. Surmade suurem hulk vanuses 5-9 eluaastat ainult suurendaks seda tendentsi .

Niisiis sobib Tlajingale - nagu Euroopa preindustriaalsetele linnadele - kõige paremini kahaneva rahvastiku mudel. Selline tulemus ei oleüllatav, sest linliku elustiili kahjulikud mõjud (nt ebastabiilsed toi duvarud ja vees ringl evad haigustekitajad) tulenevad suurest asustustihedusest ja ilmneksid tõenäol iselt asukohast sõltumata mis tahes linnalikus paigas, kus puuduvad moodsad sanitaarsed ja tervishoiualased infrastruktuurid. Teotihuacani, eriti sellevaesemat käsitööliskonda isel oomustavad terviseriskid ja kõrge suremus noores eas. See lubab järeldada, et stabiilse rahvaarvu puhul pidi linn sõl tuma maaelanikesisserändest, mis oli vajalik elanikkonna vähenemisetasakaalustamiseks. 
Tabel 4. Suremisvanuste jaotuse võrdlus Tlajinga ning A. J . Coale'i ja P. Demeny (1983) mudel itevahel.

\begin{tabular}{|c|c|c|c|c|c|c|}
\hline $\begin{array}{c}\text { Sure- } \\
\text { mus } \\
\text { vasta- } \\
\text { vas } \\
\text { vanu- } \\
\text { ses (x) }\end{array}$ & $\begin{array}{c}\text { Tlajin- } \\
\text { ga 33 }\end{array}$ & $\begin{array}{c}\text { Lääs } \\
\text { Mehed } \\
\text { 3. ta- } \\
\text { sand } \\
-\mathbf{0 , 5} \%\end{array}$ & $\begin{array}{c}\text { Põhi } \\
\text { Mehed } \\
\text { 2. ta- } \\
\text { sand } \\
-\mathbf{0 , 5} \%\end{array}$ & $\begin{array}{c}\text { Lääs } \\
\text { Mehed } \\
\text { 2. ta- } \\
\text { sand } \\
\mathbf{- 1} \%\end{array}$ & $\begin{array}{c}\text { Ida } \\
\text { Naised } \\
\mathbf{2 . ~ t a -} \\
\text { sand } \\
\mathbf{- 1} \%\end{array}$ & $\begin{array}{c}\text { Lääs } \\
\text { Naised } \\
\text { 4. ta- } \\
\text { sand } \\
+\mathbf{0 , 5} \%\end{array}$ \\
\hline $0-1$ & 31 & 31,17 & 30,54 & 30,40 & 30,33 & 31,73 \\
\hline $1-4$ & 9 & 12,49 & 16,95 & 11,82 & 10,71 & 15,82 \\
\hline $5-9$ & 5 & 2,63 & 5,15 & 2,46 & 2,58 & 3,5 \\
\hline $10-14$ & 5 & 1,83 & 2,37 & 1,74 & 1,42 & 2,52 \\
\hline
\end{tabular}

\section{Kokkuvõte}

Ajaloolistest ülestähendustest ja luustikulistest stressitunnustest saadud andmed näitavad, et vastsündinud ja lapsed kannatasid preindustriaalsetes linnades tugeva bioloogilise stressi all, mida tõenäol iselt põhjustasid endeemilised haigused ja perioodiline alatoitumus (Vanas Maailmas lisaks veel ka epideemilised nakkushaiguste puhangud). Sellest tulenevalt oli vastsündinuteja lastesuremus linnarahvastikus kõrgem kui maapiirkondades. Linlike eluviiside tekkimine mõjutas seega rahvastiku tervislikku seisundit, eriti madalama sotsiaal-majandusliku tasemega inimeste seas. Kuigi imikuteja laste suremus on alati kuulunud inimeksistentsi juurde, kandsid linnades el avad lapsevanemad üldplaanis suuremaid - ja iga järgneva põlvkonnaga süvenevaid - kaotusi kui varasemate väikeasulateelanikud. Linnastumi sega kaasnevad terviseriskid suurendasid rahvastiku kadu linnades ja need hakkasid rahvaarvu säilitamisel sõltuma sisserändest. Sedamööda, kuidas linnade elanikkond aja jooksul kasvas, suurenes ka linnastumise suhteline mõju demograafiale. Linnastumise ulatus on seega oluline tegur minevikuühiskondade tervisliku seisundi mõistmiseks. Ei tohi unustada, et vaatamata mis 


\section{Rebecca Storey}

tahes majanduslikele, poliitilisteleja sotsiaal setel eeel istele nõudsid preindustriaalsed linnad oma el anikelt suuri inimohvreid.

\section{Tänusõnad}

Tlajinga 33 pal eodemograafilist uurimust aitasid läbi viia National ScienceFoundationi toetused BNS 80-05825 ja BNS 82-04862. Minu tänu pälvivad George J. Armelagos ja E dward E. Hunt juunior abi ja juhendamise eest uurimuse läbiviimisel, William T. Sanders, kes ol i Tlajinga 33 projektijuht, ning Mehhiko Riiklik Antropoloogia ja Ajal oo I nstituut, mis andis loa väljakaevamiste teostamiseks. Tänan ka toi metajaid ja arvustajaid abivalmite märkusteja paranduste eest antud artikli koostamisel.

\section{Tõlkinud Kadri Selgeja Kairika Kärsna}

Originaal: Storey, Rebecca 1992. Preindustrial urban lifestyle and health. Huss-Ashmore, Rebecca \& Schall, J oan \& Hediger, Mary (toim). Health and LifestyleChange. MASCA Research papers in Science and Archaeology 9. Philadel phia: MASCA, University Museum of Archaeology and Anthropology, Ik 33-42.

\section{Kommentaarid}

${ }^{1}$ Inglise keeles law of urban natural decrease (tõlk).

2 Ühiskonnakihte defineeriti tegevusala kaudu.

\section{Kirjandus}

Acsádi, György \& Nemeskéri, J ános 1970. History of Human Life Span and Mortality. Budapest: Akademial Kiado.

Baker, Brenda J . \& Armelagos, George J . 1988. The origin and antiquity of Syphilis. Current Anthropology 29, Ik 703-737.

Benefer, Robert A. 1968. An Analysis of a Prehistoric Skeletal Population, Casas Grandes, Chihuahua, Mexico. Doktoriväitekiri. Austin: Anthropology Department of University of Texas.

Buikstra, J aneE . \& Konigsberg, LyleW. 1985. Pal eodemography: Critiques and controversies. American Anthropol ogist 87, Ik 316-333. 
Chandler, Tertius \& Fox, Gerald 1974. Three Thousand Years of Urban Growth. New York: Academic Press.

Childe, Gordon Vere 1950. The Urban Revolution. Town Planning Review 21: 1, Ik 3-17.

Coale, Ansley J . \& Demeny, Paul 1983. Regional Model Life Tables and Stable Populations. New York: Academic Press.

Cook, SherburneF. 1946. The Incidence and Siginificance of DiseaseAmong the Aztecs and Related Tribes. Hispanic-American Review 26, Ik 320-335.

Cowgill, George L. 1979. Teotihuacan, I nternal Militaristic Competition, and the Fall of the Classic Maya. Hammond, Norman \& Willey, Gordon Randol ph (toim). Maya Archaeol ogy and E thnohistory. Austin: University of Texas Press, Ik 51-62.

Crosby, Alfred W. jun. 1972. The Columbian Exchange: Biological and Cultural Consequences of 1492. Wesport: Greenwood Press.

Davis, Kingsley 1973. Cities and Mortality. International Population and Urban Research, Institut of International Studies. Reprint 433. Berkely: University of California.

Dobyns, Henry F. 1983. Their Number BecomeThinned: NativeAmerican Population Dynamics in Eastern North America. Knoxville: University of Tennessee Press.

Finlay, Roger 1981. Population and M etropolis: TheDemography of London 1580-1650. Cambridge: Cambridge University Press.

Fox, Richard G. 1977. Urban anthropol ogy: Cities in their cultural settings. New-J ersey: Prentice-Hall.

Goodman Alan H. \& Martin, Debra \& Armel agos, George J \& Clark, George 1984. Indications of Stress from Bones and Teeth. Cohen, M. N. \& Armelagos, George J. (toim). Paleopathol ogy at the Origins of Agriculture. Orlando: Academic Press, Ik 13-49.

Huss-Ashmore, Rebecca \& Goodman, Alan H. \& Armelagos, George J . 1982. Nutritional Inferences from Paleopathology. Schiffer, Michael B. (toim). Advances in Archaeol ogical Method and Theory 5. New York:Academic Press, Ik 385-473.

J ohansson, S. Ryan \& H orowitz, S. 1986. Estimating mortality in skeletal populations: Influence of the growth rate on the interpretation of levels and trends during the transition to agriculture. American J ournal of Physical Anthropol ogy 71, Ik 233-250.

Lewis, Thomas M cDowell Nelson \& Kneberg, MadelineD. 1946. Hiwassee Island, an archaeol ogical account of four Tennesseel ndian peoples. Knoxville: University of Tennessee Press. 


\section{Rebecca Storey}

Lovejoy, C. Owen \& Meindl, R. S. \& Pryzbeck, T. R. \& Barton, T. S. \& Hepple, K. G. \& Kotting, D. 1977. Paleodemography of the Libben Site, Ottawa County, Ohio. Science 198, Ik 329-352.

McNeill, William Hardy 1976. Plagues and People Garden City: Anchor Press.

Millon René 1981. Teotihuacan: City, state, and civilization. Sabloff, J eromy A. (toim). Supplement to theH andbook of MiddleAmerican Indians 1: Archaeology. Austin: University of Texas Press, Ik 198-243.

Mobley, Charles M. 1980. Demographic Structure of Pecos I ndians: A Model Based on Life Tables. American Antiquity 45: 3, Ik 518-530.

Newman, Marshall Thornton 1976. Aboriginal New World Epidemiology and Medical Care, and the I mpact of Old World Disease Imports. American J ournal of Physical Anthropol ogy 45: 3, Ik 667-672.

Owsley, Douglas W. \& Bradtmiller, Bruce 1983 Mortality of pregnant females in Arikara villages, osteological evidence. American J ournal of Physical Anthropology 61, Ik $331 \mathrm{jj}$.

Perrenoud, Alfred 1975. L'inégalité sociale devant la mort à Genéve au XVIII éme siécle. Population 30 (erinumber), Ik 221-243.

Sanders, William T. \& Webster, David 1988. The Mesoamerican Urban Tradition. American Anthropologist 90: 3, Ik 521-546.

Sattenspiel, Lisa \& Harpending, Henry 1983. Stable populations and skeletal age. American Antiquity 48, Ik 489-498.

Sharlin, Allan 1978. Natural Decrease in Early Modern Cities: A Reconsideration. Past and Present 79, Ik 126-138.

Sjoberg, Gideon 1960. Thepreindustrial city. New York: F ree Press.

Storey Rebecca 1985. An Estimate of M ortality in a Pre-Columbian Urban Population. American Anthropol ogist 87, Ik 519-535.

Vries, J an de 1984. European Urbanization 1500-1800. Harvard studies in urban history. Cambridge: Harvard University Press.

Wrigley, Edward Anthony 1969. Population and History. New York: McGraw Hill. 